\title{
Comunicação ambiental para o século XXI
}

José Sixto García

Investigador do Departamento CC. Comunicación da Universidade de Santiago de Compostela, Espanha, e mestrando.

E-mail: josesixtogarcia@hotmail.com

María Salgueiro Santiso

Mestre do programa Comunicación e Jornalismo da Universidade de Santiago de Compostela, Espanha.

E-mail: salgueiromaria@hotmail.com

Resumo: Cada vez mais se tem tomado consciência da necessidade de proteger e cuidar do meio ambiente. As organizações realizam trabalhos de conscientização através de campanhas de sensibilização da opinião pública. Neste artigo se realiza uma aproximação conceitual atendendo às estratégias, aos instrumentos e mecanismos que se integram dentro deste tipo de Comunicação ecológica, e se constata que se trata de ferramenta útil, atual e eficaz para construir mensagens com eficiente potencial persuasivo para uma Gestão que tem um triplo benefício: para o usuário, para a instituição e para a sociedade em geral.

Palavras-chave: comunicação ecológica, meio ambiente, responsabilidade social, educação, gestão.
Abstract: There is an increasing awareness on the need of protecting and caring for the environment. Organizations perform work through campaigns to raise awareness of the public opinion. This paper makes a conceptual approach to the strategies, tools and mechanisms that are integrated within this kind of ecological Communication and realizes that it is an useful, updated and effective tool to build messages with efficient and persuasive potential for a triple benefit Management: for the user, for the institution and for society in general.

Keywords: ecological communication, environment, social responsibility.

O estudo e a prática da comunicação não ficaram alheios à preocupação mundial com a deterioração do meio ambiente que vem ocorrendo nas últimas décadas. Essa preocupação e a conscientização social acerca da preservação do meio ambiente estão obrigando as mais diversas organizações a incorporarem mensagens ecológicas em suas propostas e estratégias de comunicação, "de forma a responderem a boa parte das expectativas da opinião pública e, também, a cumprirem com as regras e normas existentes a esse respeito"1.

Essa situação deu lugar ao surgimento da chamada comunicação ecológica, também relacionada ao marketing verde, à comunicação ambiental, ao consumo sustentável ou, ainda, ao ecomarketing, "cujo âmbito de estudo é a análise de como as atividades de comunicação incidem sobre a preservação do entorno e de

\footnotetext{
Recebido: 07.04.2009

Aprovado: 04.06.2009

1. MAD COMUNICACIÓN. Todo marketing y más... Fundamentos, principios, conceptos y estratégias (Todo marketing é ruim... Fundamentos, princípios, conceitos e estratégias). Madrid: FC Editorial, 2007. p. 749.
} 
comunicação \& educação • Ano XV • número 2 • maio/ago 2010

2. CHAMORRO, A.; MIRANDA, F. J.; RUBIO, S. El estado de la investigación sobre marketing ecológico en España: análisis de revistas españolas - 1993-2003 (A situação da investigação sobre marketing ecológico na Espanha: análises de revistas espanholas - 1993 2003). Investigaciones Europeas de Dirección y Economía de la Empresa, v. 12 , n. 2, 2006. p. 137.

3. PEATTIE, K. Environmental Marketing Management (Gestão de marketing ambiental). ondres: Pitman Publishing, 1995. p. 28

4. KILBOURNE, W. E BECKMANN, S. C. Review and Critical Assessment of Research on Marketing and the Enviroment (Análise e avaliação crítica de pesquisa sobre marketing ambiental). Journal of Marketing, v. 14, 1998 p. 513-532.

5. CHAMORRO, op. cit., p. 138. como se pode introduzir a variável ambiental nas distintas ações de marketing" ${ }^{2}$ e de comunicação. Comunicação ecológica é, portanto, "um processo de gestão integral e responsável, envolvendo antecipação e satisfação das necessidades do receptor, do público e da sociedade, de uma forma integrada e sustentável"’3.

Foi a partir dos anos 1970 que alguns investigadores, principalmente norte-americanos, começaram a contribuir para o desenvolvimento da comunicação com preocupação ecológica. A maioria desses trabalhos iniciais estava centrada nas relações entre preocupação ecológica e comportamento ecológico, especialmente a participação em sistemas de reciclagem e a caracterização de um consumidor ecológico ${ }^{4}$.

A aparição de um segundo movimento entre fins dos anos 1980 e início dos 1990 deu novo impulso aos estudos do tema, não só nos Estados Unidos, mas também nos países anglo-saxões e na Europa continental. Na Conferência Anual da Associação Americana de Marketing (AMA) de 1993, criou-se pela primeira vez uma seção especial dedicada ao marketing ecológico:

Este ressurgimento é favorecido pela aprovação de leis ambientais incidindo sobre a atividade comercial, principalmente referentes aos resíduos de embalagens (como o Decreto Töpfer, alemão, de 1991, o Decreto Lalonde, francês, de 1992, ou a Directiva 94/62/CE), pela elaboração de diversos códigos de autorregulação da comunicação ecológica (ICC, 1991; FTC, 1992; Industry Canada, 1992) e pelo desenho de sistemas de certificação ambiental (como a norma britânica BS 7750, o regulamento CEE 1836/93, a norma francesa NF X30-200 ou a norma espanhola UNE 77-801) e de selo ecológico (entre outros, la Environmental Choice canadense de 1988, a Eco-mark japonesa, o Cisne Blanco do Consejo Nórdico e o Green Seal norte-americano, todos eles em 1989, ou a Flor Europea da Unión Europea em 1992) ${ }^{5}$.

Diferentemente de posturas anteriores, em finais dos anos 1990, no âmbito das instituições, se consolida uma concepção da organização centrada não apenas nos seus objetivos econômicos e financeiros, mas numa responsabilidade social baseada, entre outras coisas, na defesa do meio ambiente e na racionalidade do consumo de energia. É a filosofia da Responsabilidade Social Empresarial (RSE) que incorpora os três aspectos do desenvolvimento sustentável da instituição - econômica, social e ambiental. Dessa forma, a Gestão se orienta para a satisfação das demandas dos diferentes grupos de interesse e as exigências do desenvolvimento sustentável que consolida as instituições e assegura sua projeção de futuro. Portanto, o conceito de organização é modificado incorporando uma série de conceitos novos como o de entorno natural e desenvolvimento sustentável. Para esse novo modelo de Gestão, muito contribuíram a administração pública e outras entidades - ONGs, grupos ecologistas e organizações de consumidores -, assim como os distintos organismos internacionais que defendem o meio ambiente, realizando um importante trabalho de conscientização social.

As atitudes que as instituições tomam a esse respeito podem ser reativas ou proativas. As instituições reativas são aquelas que se negam a aceitar as pressões ou apenas reagem quando não há outra saída, enquanto as proativas 
se adiantam às demandas dos grupos com os quais interagem - funcionários, clientes, mantenedores ou a comunidade em geral - e buscam recursos para implementar as mudanças necessárias ${ }^{6}$.

\section{O CONSUMIDOR E O PRODUTO ECOLÓGICO}

São muitos os benefícios proporcionados pelo consumo de produtos ecológicos. Esses devem também ser aceitos como mais duradouros, uma vez que as vantagens da preservação ambiental têm de ser calculadas a médio e longo prazo. Além disso, esses produtos dão ao consumidor uma sensação de autovalorização que advém da consciência da tomada de uma decisão ecológica.

Esses consumidores agem de acordo com suas crenças e valores, desenvolvidos no tempo e resultantes de processos de aprendizagem. Em vista disso, devemos considerar o seguinte em relação ao consumo ecológico:

- A consciência ecológica - formada de crenças e conhecimentos ecológicos, que se podem incrementar com a chegada de informações sobre os benefícios desse tipo de consumo.

- A ecopostura - preferência por produtos ecológicos. É influenciada pelo grupo social e pela educação e informação recebida.

- A ecoatividade - tendência a atuar ecologicamente que se manifesta como parte da personalidade do consumidor.

\section{O DUPLO CONDICIONAMENTO DA COMUNICAÇÃO ECOLÓGICA: ECONÔMICA E SOCIAL}

A comunicação ecológica pode ser conceituada a partir de duas referências: a institucional e a social. De uma perspectiva social, é parte integrante da responsabilidade social, quer dizer, do conjunto de atividades que buscam estimular e facilitar a aceitação de ideias, atitudes ou comportamentos sociais que se consideram benéficos à sociedade em geral ou que buscam reprimir conceitos, atitudes ou comportamentos considerados prejudiciais. Assim sendo, os principais objetivos para os quais se volta esse tipo de comunicação são ${ }^{7}$ os seguintes:

- Educar e informar sobre temas relativos ao meio ambiente. As diversas campanhas promovidas pela administração pública, relativas à reciclagem de lixo e à coleta seletiva são um bom exemplo desse tipo de comunicação.

- Estimular ações em defesa do meio ambiente. As diferentes campanhas de conscientização sobre a economia de água que, desde 1995, vêm sendo implementadas pelo ministério espanhol do meio ambiente perseguem esse objetivo.

- Modificar comportamentos nocivos ao entorno natural. Neste objetivo se enquadram as diversas campanhas institucionais de informação e
6. RODRÍGUEZ BADAL, M. A.; RICART, Joan Enric (1998). Dirección medioambiental de la empresa (Admistração meio ambiental da empresa). Barcelona: Gestión, 2000 7. MAD COMUNICACIÓN, op. cit. 
comunicação \& educação • Ano XV • número 2 • maio/ago 2010

sensibilização contra queimadas e a favor da prevenção de incêndios florestais, promovidas por diferentes administrações.

- Modificar valores sociais. Entre os exemplos que podemos citar de campanhas que visam a esse objetivo estão as que defendem o respeito ao tamanho mínimo dos peixes a serem pescados e consumidos, de acordo com o determinado anualmente pelo Ministério da Agricultura, Pesca e Alimentação.

É preciso ter em conta que a comunicação ecológica implica descomunicar, na medida em que envolve ações e campanhas que visam desestimular atitudes nos usuários, seja de forma geral ou parcial, seja temporária ou permanentemente. Isto é, podem-se desenvolver atividades de descomunicação e desmarketing para desestimular a compra de produtos que se usam uma única vez, insistindo-se nas vantagens ambientais e econômicas dos produtos duradouros ou reutilizáveis ${ }^{8}$. Como exemplo, podemos citar as campanhas que promovem o uso de sacolas de pano em lugar das de plástico, que receberam o respaldo de governos como os da China e o da Irlanda, com a promulgação de leis que proíbem seu uso.

Por outro lado, de um ponto de vista empresarial, a comunicação ecológica é aquela que aplicam as empresas que adotam um enfoque social para suas atividades e negócios, buscando satisfazer, ao mesmo tempo, as necessidades sociais e as de seus consumidores. Para tanto, podemos defini-la como o processo de planejamento, implantação e controle de uma política de produção, distribuição e comunicação "que facilite e permita que as necessidades dos clientes sejam satisfeitas, que os objetivos da organização sejam alcançados e que o processo produza o menor impacto possível no ecossistema". Campanhas como as de alguns fabricantes de automóveis que promovem a redução nas emissões de $\mathrm{CO}_{2}$ ou das grandes corporações energéticas - Endesa e Repsol - que fizeram da sustentabilidade um dos pilares de sua estratégia publicitária são alguns dos exemplos da importância cada vez maior que tem a comunicação ecológica no âmbito das empresas.

8. LORENZO, María Montserrat. Marketing ecológico y sistemas de gestión ambiental: conceptos y estrategias empresariais (Marketing ecológico e sistemas de gestão ambiental: conceitos e estratégias empresarias) Revista Galega de Economía, v. 11, n. 2, p. 4 2002.

9. MAD COMUNICAClÓN, op. cit., p. 750.

\section{ESTRATÉGIAS, FUNÇÕES E USUÁRIOS VERDES}

A comunicação ambiental nasce da essencialidade de as diferentes instituições se adaptarem às demandas ecológicas da sociedade e dos organismos reguladores de suas atividades e, portanto, contribuirem e obterem um desenvolvimento sustentável, de maneira a corresponder às necessidades de seus consumidores e usuários, sem comprometer a capacidade de satisfazer, do mesmo modo, as próximas e futuras gerações.

Qualquer organização que desempenhe uma atividade na sociedade é responsável também diante dela e, por isso, se os serviços e atividades que desenvolve prejudicam de alguma forma as pessoas, ela deve eliminar ou reduzir os danos causados ao mínimo possível. Neste sentido, a organização "considerando a responsabilidade social que deve assumir, deve fazer um balanço entre 
a necessidade de seu público e o interesse e bem-estar da sociedade em geral no presente e no futuro" ${ }^{\prime 10}$.

São múltiplas e variadas as estratégias institucionais e públicas que adotaram o caminho da comunicação ambiental para a promoção de suas atividades e promoção de serviços. Entre elas podemos citar a desenvolvida pela Iberdrola Renovables que pôs em marcha o programa Huella Verde, que tem como objetivo a redução de emissão de $\mathrm{CO}_{2}$ nos lares, através da adoção de medidas aplicadas à vida cotidiana em diferentes estações do ano.

De qualquer modo, para que se possa aplicar de forma adequada e efetiva os princípios da comunicação ambiental é preciso que a organização desenvolva um plano específico que inclua os seguintes aspectos:

- em primeiro lugar, que se faça uma declaração expressa para a proteção do meio ambiente;

- que essas intenções façam parte da organização estratégica da instituição;

- que haja sintonia entre as atividades da instituição e as preocupações ambientais.

Neste aspecto, é paradigmático o exemplo do Triodos Bank, com sede na Holanda e sucursais em diversos países, entre os quais a Espanha, que investe somente em projetos sociais, culturais ou ambientais. Alguns de seus microcréditos se destinam a mulheres da Sudáfrica ou à instalação de sistemas de aquecimento por energia solar em Madri.

A comunicação ecológica deve assumir como objetivo principal as seguintes funções:

1 - Orientar a escolha do público consumidor ou usuário. Atualmente os consumidores e usuários parecem estar dispostos a reduzir os níveis de consumo e, para alcançá-lo, um dos objetivos prioritários é o de transformar os hábitos de consumo através da conscientização ambiental. Isto é, trata-se de conseguir que o usuário tenha preocupações ecológicas sempre que for consumir um produto ou serviço. Daí a importância das campanhas ambientais que incidem na necessidade da educação do consumidor, quanto aos problemas e soluções ecológicas. Conscientes desse fato, organizações como o Greenpeace orientam suas linhas de trabalho para a educação ambiental - divulgar campanhas, trabalhar com os mais jovens e programar ações em escolas são algumas das propostas -, já que se trata de ferramentas fundamentais para a sensibilização e a mudança social.

2 - Reorientar os processos de comunicação. Para a integração efetiva desses processos é necessário incorporar os objetivos ecológicos a cada um dos seguintes instrumentos: a política de produção, de preços, de distribuição e, principalmente, a de comunicação.

Assim, é preciso que as decisões resultem no desenvolvimento de produtos que minimizem o consumo de recursos escassos e a geração de resíduos, sem, entretanto, deixar de satisfazer o consumidor. De fato, um produto ecológico cumpre as mesmas funções de um produto equivalente, porém os danos que causa ao meio ambiente são menores ao largo de todo seu ciclo de vida ${ }^{11}$. Por
10. LORENZO, op. cit., p. 6.

11. CALOMARDE, J. V. Marketing ecológico. Madrid: Pirâmide, 2000. 
comunicação \& educação • Ano XV • número 2 • maio/ago 2010

12. Para mais informações, consultar HOPFENBECK, W. Dirección y marketing ecológicos (Administração e marketing ecológicos). Bilbao: Deusto, 1993.

13. MIQUEL, S.; BIGNÉ, J. E. Marketing y medioambiente: una aproximación teórica revisada (Marketing e meio ambiente: uma aproximação teórica revisada). Revista Europea de Dirección y Economía de la Empresa, v. 6, n. 3, p. 47-62, 1997.

14. ZIKMUND, W.; STANTON, W. J. Recycling Solid Wastes: a Channels-of-Distribution Problem (Reciclagem de detritos sólidos: um problema de canais de distribuição). Journal of Marketing, v. 35, n. 3, p. 34-39, 1971.

15. CALOMARDE, op. cit. exemplo, no caso dos produtos de limpeza, o consumidor compra um para que sua roupa fique limpa, porém, se a empresa o fabrica com ingredientes vegetais de alta biodegradabilidade e não tóxicos ao meio ambiente, trata-se de um produto ecológico, o que conferirá a ele um outro valor que pode determinar a preferência do consumidor. Hopfenbeck ${ }^{12}$ afirma que um produto ecológico deve causar o mínimo de prejuízos ao meio ambiente na sua produção, no consumo assim como em sua eliminação.

Miquel e Bigné ${ }^{13}$ citam as bases nas quais se concebe um produto ecológico e as relacionam com o produto em si e seus atributos básicos, o processo produtivo e os materiais usados, a embalagem em relação à sua reutilização, a reciclagem e a redução de componentes e, finalmente, a eliminação do produto utilizado e sua reutilização, reciclagem ou reparação.

Quanto à distribuição, recordamos que se deve colocar o produto ecológico à disposição do consumidor em lugar próprio, num momento oportuno e em quantidade adequada. A distribuição deve contentar dois aspectos. Em primeiro lugar, é preciso encontrar canais de distribuição idôneos e, em segundo lugar, analisar os meios existentes de reciclagem, para possibilitar o retorno desses produtos para reutilização e reciclagem, como por exemplo os pontos de recolha de eletrodomésticos. A reciclagem é fundamentalmente um problema de canais de distribuição ${ }^{14}$, baseado em um dos seguintes fatores:

- Altruísmo.

- Incentivos econômicos. O Plan Vive (Veículo Inovador-Veículo Ecológico) do Ministério da Indústria da Espanha serve de exemplo por subvencionar os custos de financiamento para aquisição de veículos novos desde que o consumidor tire de circulação veículos com mais de quinze anos de uso.

- Medidas legislativas que, ainda tendo como exemplo os eletrodomésticos, façam referência à Diretiva Europeia 2002/96/CE sobre Reciclagem de Aparatos Elétricos e Eletrônicos (RAEE), aprovada em 2003 e integrada à legislação espanhola em 2005, que implantava diversos objetivos para prevenir, nos países membros, a geração de resíduos desses aparatos e fomentar a reutilização, a reciclagem e outras formas de valorização, reduzindo a mera eliminação. Seja como for, estabelecer canais de distribuição e reciclagem de produtos é sempre uma tarefa complexa, porque implica inverter a ordem tradicional, de forma a transformar o consumidor em produtor e o fabricante em comprador.

A política de comunicação ecológica deverá informar sobre os atributos dos produtos, sobre os benefícios ao meio ambiente e transmitir a ideia de organização bem informada e ativa em temas ambientais ${ }^{15}$. De qualquer forma, tem que se levar em conta que o receptor não é apenas o usuário do produto, mas todos os grupos de interesse internos e externos e a sociedade em geral.

3 - Reorganizar o comportamento da instituição. A comunicação ecológica compreende não só um conjunto de técnicas destinadas a realizar o desenho e a comercialização dos produtos que resultem menos prejudiciais ao entorno 
e à sociedade, como também a ideia de que é uma forma a mais de conceber as relações de troca, baseada na satisfação das três partes envolvidas: o consumidor, a instituição e o meio ambiente.

\section{CONSIDERAÇÕES FINAIS}

A necessidade de reduzir o impacto ambiental de um produto ou serviço ou de seu processo de elaboração não constitui necessariamente uma limitação à atividade de uma organização ou instituição. Pode, antes de qualquer coisa, representar uma oportunidade estratégica no marco de uma gestão efetiva. A comunicação ecológica é uma ferramenta indispensável nessa direção, no sentido de informar o consumidor das consequências ecológicas de seus hábitos de compra, tendo, nesse sentido, um importante papel educativo. Mas há também a função de modificar os hábitos existentes nas instituições e, assim, resultar num triplo benefício para o usuário consumidor, para a instituição e para a sociedade em geral.

\section{REFERÊNCIAS BIBLIOGRÁFICAS}

CALOMARDE, J. V. Marketing ecológico. Madrid: Pirâmide, 2000.

CHAMORRO, A.; MIRANDA, F. J.; RUBIO, S. El estado de la investigación sobre marketing ecológico en España: análisis de revistas españolas - 1993-2003 (A situação da investigação sobre marketing ecológico na Espanha: análises de revistas espanholas - 1993-2003). Investigaciones Europeas de Dirección y Economía de la Empresa, v. 12, n. 2, 2006.

HOPFENBECK, W. Dirección y marketing ecológicos (Administração e marketing ecológicos). Bilbao: Deusto, 1993.

KILBOURNE, W. E.; BECKMANN, S. C. Review and Critical Assessment of Research on Marketing and the Environment (Análise e avaliação crítica de pesquisa sobre marketing ambiental). Journal of Marketing, v. 14, 1998.

LORENZO, María Montserrat. Marketing ecológico y sistemas de gestión ambiental: conceptos y estrategias empresariais (Marketing ecológico e sistemas de gestão ambiental: conceitos e estratégias empresarias). Revista Galega de Economía, v. 11, n. 2, 2002.

MAD COMUNICACIÓN. Todo marketing y más... Fundamentos, principios, conceptos y estrategias (Todo marketing é ruim... Fundamentos, princípios, conceitos e estratégias). Madrid: FC Editorial, 2007.

MIQUEL, S.; BIGNÉ, J. E. Marketing y medioambiente: una aproximación teórica revisada (Marketing e meio ambiente: uma aproximação teórica revisada). Revista Europea de Dirección y Economía de la Empresa, v. 6, n. 3, 1997. 
comunicação \& educação • Ano XV • número 2 • maio/ago 2010

PEATTIE, K. Environmental Marketing Management (Gestão de marketing ambiental). London: Pitman Publishing, 1995.

RODRÍGUEZ BADAL, M. A.; RICART, JOAN ENRIC (1998). Dirección medioambiental de la empresa (Administração meio ambiental da empresa). Barcelona: Gestión, 2000.

ZIKMUND, W.; STANTON, W. J. Recycling Solid Wastes: a Channels-ofDistribution Problem (Reciclagem de detritos sólidos: um problema de canais de distribuição). Journal of Marketing, v. 35, n. 3, 1971. 